\title{
Comentarios
}

\section{Soberanía y casos judiciales internacionales}

Quisiera empezar citando un párrafo del pensamiento del papa Juan Pablo II que asumo con claridad: "Los crímenes contra la humanidad no pueden ser considerados asuntos internos de una nación" (Mensaje de Juan Pablo II para la Jornada mundial de la paz, 1 de enero de 2000, n 7). Este modo de pensar viene gestándose en la historia de las leyes desde hace ya muchos años. Francisco de Vitoria, padre, entre otros, del derecho internacional, limitaba los derechos de los vencedores en las guerras y rechazaba la arbitrariedad de los mismos, así como tachaba de herética la tesis que defendía la licitud de matar inocentes durante las guerras, en previsión a futuras rebeliones. El recurso a la autoridad religiosa era, en aquel tiempo, el único camino aceptado para evitar desmanes. Bartolomé de Las Casas, en su defensa de los indios, decía incluso que con el actuar brutal de los conquistadores "aniquilase y piérdese... el verdadero título y señorío del Rey" (Bartolomé de Las Casas, "Tratado Tercero, Prólogo de las réplicas que hace contra el Dr. Sepúlveda"). En otras palabras, que la comisión de acciones de barbarie limitaba y eliminaba los títulos de soberanía de aquel entonces.

Este modo de pensar, expresados como semilla todavía hace quinientos años, se fue abriendo paso con dificultad en medio de nacionalismos muchas veces exacerbados. Y no llega a su madurez, sino hasta después de terribles sufrimientos de la humanidad. Las declaraciones de derechos en Inglateпа, Francia y Estados Unidos, aunque ofrecieron un excelente punto de partida para la universalización de lo que hoy llamamos derechos humanos, estuvieron todavía muy sujetas al nacionalismo e incluso a las políticas imperiales de estos países. Las luchas contra la abolición de la esclavitud, el surgimiento de la Cruz Roja Intemacional, la aparición de tratados internacionales que garantizaban determinados derechos, fueron los pasos previos. Incluso la claridad con la que se afirmaba, tras la revolución francesa, que la soberanía estaba en el pueblo, se tomaba posteriormente inconsecuente al establecer cierto tipo de guardianes de la soberanía que eran capaces de usar sus facultades delegadas contra el mismo pueblo que había hecho la delegación. Pero sólo el absurdo, la dureza y la irracionalidad de la segunda guerra mundial, con toda su crueldad, incluidos los campos de exterminio, forzaron el reconocimiento de derechos universales independientemente de la raza, religión o nacionalidad.

Una vez establecidos los derechos humanos como patrimonio universal, los tratados fueron creciendo y la mentalidad se fue abriendo cada vez más a considerar determinados crímenes como imprescriptibles y como perseguibles en cualquier parte del globo. Los procesos de globalización han aumentado en el ámbito ciudadano la conciencia de la dimensión internacional de la justicia. La Interpol, los pactos para luchar mancomunadamente contra delitos como el tráfico ilícito de droga, favorecen la percepción de que los crímenes cometidos en determinados países pueden ser perseguidos $\mathrm{e}$ incluso juzgados en otros diferentes. El surgimiento del Tribunal Penal Internacional es, finalmente, una derivación clara de esa gran herencia del siglo $\mathrm{XX}$, que es la convicción de la igual dignidad humana.

En este contexto nos estamos preguntando ahora por la conveniencia de juicios internaciona- 
les y de si éstos pueden dañar la soberanía de las naciones. En primer lugar, hay que decir que el concepto y el valor de soberanía nunca han sido considerados como absolutos. La Constitución de El Salvador al reconocer "a la persona como el origen y el fin de la actividad del Estado" (Título I, Artículo 1), establece ya una limitación a la propia soberanía. El Estado, y con él la soberanía, sin la cual no existiría el Estado, está al servicio de la persona y no por encima de ella. Si el servicio a la persona es deficiente en lo que respecta a derechos fundamentales, sería lógico que, agotados todos los recursos, la persona acudiera a otro lugar en el cual se le pueda hacer justicia.

Establecido este principio, puede alegarse, y con razón en algunas ocasiones, que la proliferación de juicios internacionales supondría con frecuencia una ventaja para aquellas personas o instituciones que tengan capacidad, apoyo y conocimiento adecuado para entablarlos. Incluso podría hablarse de un cierto imperialismo, según el cual los países ricos del norte podrían juzgar las violaciones a los derechos humanos acaecidas en el sur y seguir, al mismo tiempo, comerciando en armamento con los países violadores de tales derechos. $\mathrm{O}$ simplemente respaldando con medidas económicas y políticas a los mismos gobiernos a cuyos representantes se enjuicia por violaciones, una vez abandonado el poder. Y más allá de las relaciones entre países, la posibilidad de juicios internacionales que enfrenten a transnacionales con países pequeños no deja de producir escalofríos. Baste con comparar los aproximadamente 12000 millones del producto interno bruto de El Salvador con los volúmenes de ventas de las transnacionales que duplican o triplican dicha cantidad.

Evidentemente, esto nos muestra una situación mundial en la que la hipocresía política tiene todavía demasiado peso. Y donde hay también que perfilar y mejorar los procedimientos de justicia para que los pobres no se vean en desventaja.

En el caso de El Salvador, la doctrina es la misma. Las violaciones a los derechos humanos han sido muy duras en el país, y aunque todo el mundo dice de palabra que fueron horrendas, apenas se encuentra coherencia entre dicha afirmación y lo que podríamos llamar consecuencias lógicas. Por poner un ejemplo, si la masacre de 132 niños con una edad promedio de seis años en El Mozote es terrible, como en realidad lo es, ipor qué no hay esfuerzos mayores por dedicarles algún tipo de monumento o calle, o de darle nombre conmemorativo a algún edificio en honor a estas víctimas inocentes? No estoy hablando ni siquiera de juicios, sino de compensación moral. Pero la realidad salvadoreña es, en este sentido, triste. A las víctimas no se las respeta ni hay conciencia de que se les deba, como deber de justicia, devolver su dignidad. Lo cual no es extraño porque también son, en muchos aspectos, víctimas el 50 por ciento de la población sumido en pobreza y no hay mayores esfuerzos reales en la lucha contra la misma.

Esta falta de conciencia ante el deber de la reparación, y la superficialidad con la que se confunde el olvido irresponsable con el perdón, hacen a El Salvador más sensible y más débil frente a juicios internacionales. Por ser un país pequeño y con recursos escasos, y al mismo tiempo con abundante impunidad oficial, sus ciudadanos, en la medida en la que han cometido abusos de poder o han sido cómplices en la violación de derechos humanos, pueden ser sometidos con facilidad a procesos internacionales. Y con frecuencia en una situación en la que los recursos de las organizaciones no gubernamentales extranjeras defensoras de derechos humanos superan los recursos de los ciudadanos salvadoreños. En otras palabras, éstos quedan en una situación de relativa inferioridad. De hecho, en este momento ya se está dando el caso de algún funcionario en activo que tiene orden de detención internacional, y de otros ex funcionarios que están siendo sometidos a juicio o tienen también orden de detención internacional. La absolución en el caso de las monjas de Maryknoll no es más que la antesala de nuevos juicios a los mismos personajes, esta vez por tortura.

Es normal que estas circunstancias creen nerviosismo e inquietud en el país, pero también es necesario que estos acontecimientos nos hagan reflexionar. De hecho, el enjuiciamiento de los dos ex ministros salvadoreños en Estados Unidos tuvo como precedente un intento de abrir el juicio de las religiosas estadounidenses contra los autores intelectuales, en El Salvador. Pero en aquel momento se denegó la petición por parte de la Fiscalía General, entre otros. No es raro, entonces, que quienes tienen derecho a la verdad y a la justicia abran casos en donde la justicia los escuche.

Para empezar, en el país debía haber mayor preocupación por las víctimas civiles del conflicto. Los combatientes del FMLN y los miembros del ejército pueden recordar a sus supuestos héroes, si 
es que en un conflicto civil entre hermanos puede haber heroísmo. Pero a las víctimas civiles debería recordarlas el Estado en su conjunto. Tal vez algunas víctimas tienen detrás a instituciones con cierto poder e influencia que puedan promover su recuerdo, pero ello no exime de responsabilidad al Estado. Pues estando al servicio de la persona, no puede tratar como "no-personas" a quienes fueron despojados de su dignidad, a través de torturas, vejaciones o muerte, de un modo injusto y criminal. Esta reparación moral y este funcionamiento adecuado del Estado, si se da, pone los presupuestos para una auténtica reconciliación. El hecho de reconocer la dignidad de las víctimas, honrándolas con honores simbólicos, desde poner su nombre a lugares públicos hasta la declaración de un día dedicado a ellas, es un primer paso. Y no sólo para reconciliarse con ellas o sus supervivientes, sino incluso con la propia historia salvadoreña. Pues mientras no se reconozca públicamente el valor de las víctimas, se estará defendiendo una historia donde la ley del más fuerte ha imperado y dominado las relaciones entre los seres humanos. Y la ley del más fuerte lleva siempre a la confrontación o a la esclavitud, dos elementos reñidos con el concepto contemporáneo de sociedad democrática.

Pero si se quieren evadir juicios internacionales, no basta con darle la debida reparación moral a las víctimas, sino que es necesario que las instituciones internas funcionen y que los problemas se traten con racionalidad. Si una Fiscalía General con el monopolio de la acción penal puede impunemente tomar decisiones antijurídicas, mantenerlas, bloquear el funcionamiento adecuado de las leyes y actuar mal a sabiendas, o con ignorancia inexcusable, los lamentos ante el hecho de que las víctimas acudan a tribunales internacionales no dejan de ser más que el rostro visible e hipócrita de la tradición de impunidad. Si queremos que a nuestros ex funcionarios no los enjuicien en el exterior, tenemos que establecer un orden jurídico donde las leyes se respeten escrupulosamente y donde las instituciones no jueguen en favor de los más poderosos de un modo casi automático. Mientras la situación socioeconómica de El Salvador siga pesando en nuestro sistema judicial, no tenemos demasiada autoridad moral para reclamar ante quienes nos superan en el exterior en fuerza o en influencia. Porque, en efecto, para nadie es un secreto que el 20 por ciento más rico de nuestro país se queda con el 56.5 por ciento del ingreso nacional, mientras que el 20 por ciento más pobre recibe sola-

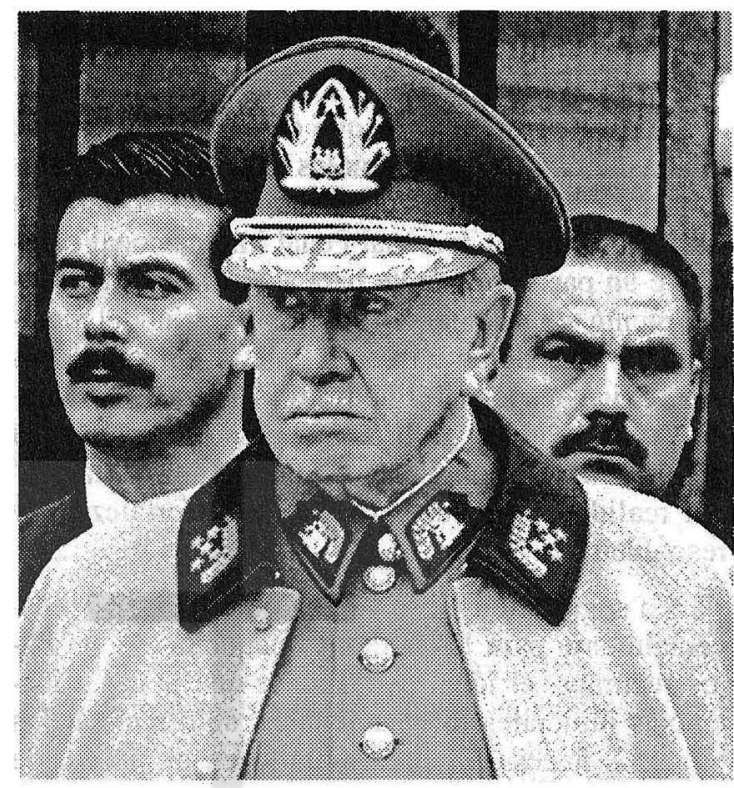

mente el 3.4 por ciento. Y hasta ahora difícilmente una persona del 20 por ciento más pobre puede tener éxito en nuestro sistema judicial pleiteando contra alguien del 20 por ciento superior.

Así las cosas, es importante recordar que a las instituciones las hacemos y las fortalecemos todos. Que invertir en institucionalidad, en desarrollo, efectividad y agilidad de la misma, nos beneficia a todos, dentro y fuera de nuestro país. Cierto tipo de terrorismo periodístico, de campañas de prenisa en el que la libertad de expresión queda prácticamente eliminada, de afirmaciones que repiten un vocabulario semejante al que utilizaban aquellos que gustaban de la amenaza, no ayudan al funcionamiento institucional. Y si ese tipo de campañas y la avalancha de críticas desatada se realizan cuando las instituciones empiezan a tratar de funcionar, tampoco alientan al ciudadano a utilizar el marco legal salvadoreño. Gritar en el interior del país que quienes llevan los juicios al exterior son parte de una conspiración contra el país no ayuda ni a crecer en democracia, ni a mejorar la imagen supuestamente dañada por un juicio internacional. $Y$ en el interior, no deja de ser llamativo que aquellos que hace todavía muy poco tiempo no se tentaban la ropa a la hora de violar derechos humanos, sean ahora los que más gritan hablando de perdón, de venganza, de odio y de oscuros intereses, cuando simplemente se está pidiendo que se apliquen leyes vigentes (incluida la Constitución) y que las instituciones funcionen. 
En este contexto, y para terminar quisiera repetir en forma de tesis lo expuesto hasta el momento.

En primer lugar, creo que debemos afirmar que las instancias internacionales son fundamentales para defender los derechos humanos. Acelerar la conformación del Tribunal Penal Intemacional constituye un paso importante para asegurar lo que habitualmente denominamos como imperio del derecho. La afirmación básica de que la humanidad es una, exige responsabilidad mundial ante lo humano. $Y$ en la aldea global es necesaria una justicia con instancias globalizadas. Que no anulen la propia realidad jurídica, pero que sí la fortalezcan y respalden.

En segundo lugar, para cualquier país, pero especialmente para las naciones pequeñas y con bajos recursos, el ideal es no tener que llegar a instancias judiciales internacionales, sino realizar los procesos necesarios para evitarlo en el ámbito de la mediación y el diálogo. O si estas instancias fracasan, en el marco del sistema judicial, los tribunales internacionales deberían ser garantía de los derechos de nuestro país y no lugar para solventar problemas internos. Un tribunal penal internacional es indispensable, por ejemplo, para que ningún Estado pueda dar un trato aberrante a emigrantes o a personas que intenten pasar ilegalmente fronteras. Ahí deberíamos ir para defender a los salvadoreños, si se diera el caso, cuando en otro Estado se los humille y maltrate, denegando posteriormente justicia. Pero los asuritos internos, al menos idealmente, deberían ser resueltos por la vía del diálogo en el país, o si esto no fuera posible, a través de instituciones judiciales fuertes y justas.

Para ello es indispensable, en tercer lugar, acrecentar la cultura de paz, que es al mismo tiempo una cultura democrática y una cultura de la legalidad en el país. Las influencias, el chantaje, la amenaza, las campañas de prensa dispuestas a acabar con la fama de las personas, siguen presentes en nuestro modo de actuar. Educar para la democracia y para una cultura de paz, invocar un gobierno de leyes y no de favoritismos y amistades, fortalecer aquellas instituciones que pueden acrecentar este tipo de cultura, acostumbrarnos a deducir responsabilidades en vez de huir de las mismas, asumir errores, sean propios o ajenos, es una tarea indispensable, tanto para la paz del país cumo para su estabilidad y su desarrollo. La cultura de paz se asienta siempre sobre dos pilares, la defensa de la vida, en toda su amplitud, y la búsque- da de soluciones pacíficas a los conflictos. La defensa de la vida tiene su más alta expresión en nuestros días en la promoción y protección de los derechos humanos. La solución pacífica de los conflictos depende siempre, en primera instancia, de la existencia de mecanismos de mediación adecuados, como por ejemplo, la Procuraduría de los Derechos Humanos a nivel estatal. Pero también son necesarias otro tipo de defensorías importantes en la sociedad civil (por ejemplo, el defensor del lector en los periódicos, o del estudiante en las universidades). Iniciar un proceso de promoción y desarrollo de estas instituciones es un paso previo importante.

La promoción de la cultura de la legalidad se debe sumar a estos esfuerzos, no tanto en la forma de un conocimiento formal de las leyes, sino como camino de respeto a la convivencia ciudadana y como vía educativa para asumir responsabilidades. Incluso, los actos más gratuitos, como el amor, el perdón, la misericordia, generan responsabilidades. Impulsar estructuras de legalidad (que nos gobiernen leyes y no personas, como dirían los clásicos de la política), implica también promover y desarrollar un modo de aceptar acuerdos básicos, plasmados en leyes, que nos lleven a una convivencia en la que se pueda responder adecuadamente por los actos de cada uno. Pero la cultura legal es todavía demasiado débil en nuestro país. Baste con observar elementos tan básicos como el tráfico, la práctica constante de evasión de impuestos en bastantes sectores, o la impunidad que demuestran los índices tan bajos de resoluciones judiciales favorables a las víctimas de delitos graves. Mayor voluntad política, ejercicio más riguroso de la autoridad y desarrollo institucional, son elementos claves en el desarrollo de esta nueva cultura.

Mientras el desarrollo de esta cultura no se dé, los casos internacionales contra ciudadanos de $\mathrm{El}$ Salvador, especialmente de aquellos vinculados al ejercicio de la autoridad, no podrán ser vistos como un atentado contra la soberanía, sino en realidad como apoyo a una nueva cultura en la que se desarrollen y aúnen la paz, la institucionalidad, la legalidad y el ejercicio democrático de los derechos.

\section{José M. Tojeira S. J. Rector de la Universidad Centroamericana "José Simeón Cañas"}

